\title{
Saberes previos y sentido común en la enseñanza-aprendizaje de las ciencias: un enfoque desde la historia epistemológica de las ciencias Jorge Márquez Valderrama*
}

Prior knowledge and common sense in teaching-learning sciences: an approach from epistemological history of sciences

\begin{abstract}
Aquel que no comprende, y lo dice, es aquel que da más evidentemente prueba de inteligencia, pues ha comprendido que no ha comprendido y eso es lo más difícil de comprender. Agradezcámosle, pues ha hecho un regalo a todos aquellos que a su alrededor, creían equivocadamente, haber comprendido
\end{abstract}

Raymond Devos

\section{Resumen}

Este artículo propone una apertura de los educadores hacia la reflexión sobre los saberes previos de ellos mismos y de sus educandos, a partir de la consideración de estos saberes como un elemento del entorno vital cotidiano, de la construcción del sentido común y de la comunicación en los procesos de enseñanza-aprendizaje. El punto de partida es la pregunta: ¿es concebible algún intento por cultivar la actitud científica sin cultivar la actitud crítica? La actitud de los maestros de ciencias hacia el conocimiento también se transmite a los jóvenes que los toman por modelo. En la tarea de convertir el aula en un lugar de trabajo del pensamiento y de cambio de actitudes hacia la investigación, hay que trabajar en la transformación de la imagen de ciencia de los mismos profesores. Se propone una sencilla reflexión, elaborada a partir de la experiencia con la historia epistemológica de las ciencias.

Pavavras chaves: historia epistemológica de las ciencias, actitud científica, enseñanzaaprendizaje

\footnotetext{
Jorge Márquez Valderrama: Historiador de la Universidad Nacional de Colombia. Doctor en Enseñanza y Difusión de las Ciencias y las Técnicas de la Universidad París XI. Profesor asociado del Departamento de Estudios Filosóficos y Culturales de la Universidad Nacional de Colombia, sede Medellín. Líder del Grupo de Investigación producción, circulación y apropiación de saberes, PROCIRCAS. Su obra más reciente es Ciencia, riesgos colectivos y prensa escrita: el caso del sida en Colombia, Medellín, Universidad Nacional de Colombia, 2008.
} 


\begin{abstract}
This article proposes that teachers should be open to reflecting upon their prior knowledge (know-how, skills) and that of their students. This should be done based on the consideration of the knowledge as an element of the vital daily environment, on the construction of common sense and on the communication of the teaching-learning processes. The starting point is the question: is any attempt for encouraging the scientific attitude conceivable without encouraging a critical attitude? The attitude of science teachers towards knowledge is also transmitted to the students, who take them as models. In order to turn the classrooms into a place where the work of thoughts and the change in attitudes towards research are possible, it is necessary to shape the transformation of the image of science that the teachers themselves have. A simple reflection is proposed, based on the experience with the epistemological history of sciences.
\end{abstract}

Key-Words:epistemological history of sciences, scientific attitude, teaching-learning

\title{
Introducción
}

El objetivo de este artículo es proponer una apertura de los educadores hacia la reflexión sobre los saberes previos de ellos mismos y de sus educandos, a partir de la consideración de estos saberes como un elemento del entorno vital cotidiano, de la construcción del sentido común y de la comunicación en los procesos de enseñanza-aprendizaje.

¿Es concebible un intento por cultivar la actitud científica sin cultivar la actitud crítica? Pienso que no. Por eso, propongo a los maestros de ciencias comenzar siempre, en su quehacer cotidiano, por interrogar, de manera personal y concreta, la tarea que se proponen realizar con los educandos. Primero deben tener en cuenta que su propia actitud hacia el conocimiento es lo que más directamente transmiten a los jóvenes que los toman por modelo.

En ese sentido, entre las competencias por desarrollar está, ante todo, la de saber convertir el aula en un lugar de trabajo del pensamiento y de cambio de actitudes hacia la 
investigación. Para lograrlo, primero hay que apuntar hacia la transformación de la imagen de ciencia que los profesores tenemos y transmitimos. Propongo, pues, como una contribución a esta tarea, unas sencillas reflexiones, elaboradas a partir de mi experiencia con la historia epistemológica de las ciencias.

La tan criticada enseñanza tradicional de las ciencias transmite fácilmente concepciones de la ciencia apartadas de los verdaderos procesos de construcción y evolución de los conocimientos científicos. Concepciones pobres en ciencia y ricas en mitos, que a su vez desmejoran y tergiversan en los estudiantes su imagen de los científicos y de la actividad científica, forman uno de los principales obstáculos para la tarea de cultivar, entre los jóvenes, una nueva actitud hacia la ciencia que estimule su aprendizaje y que les permita asumir una actitud crítica frente a ella. Desafortunadamente, la pantalla que impide percibir de otro modo la actividad científica es la enseñanza científica misma, al verse reducida a la presentación de resultados de la ciencia, sin permitir a los estudiantes acercarse a los procesos, prácticas y formas de interrogar propios de la ciencia. Se refuerza así una imagen del tal "método científico" y de la ciencia, que llega a erigirse en una especie de mito según el cual la actividad científica está reservada a unos pocos cerebros excepcionales.

Una educación científica concentrada únicamente en la transmisión de conocimientos, puede llegar a ser un obstáculo para el cultivo de la actitud científica en el medio escolar. Queremos atacar de modo reflexivo ese obstáculo. Primero, desde un examen de las concepciones previas de los educadores, casi siempre basadas en concepciones epistemológicas “de sentido común". Luego, desde la reflexión epistemológica sobre el papel de la ciencia en el medio escolar. Y, finalmente, desde la historia epistemológica de los conceptos científicos como herramienta para la enseñanza de las ciencias y para la crítica del sentido común, a partir del cultivo de la actitud científica.

La renovación de la enseñanza de las ciencias exige cambiar las prácticas de los profesores y alumnos en clase de ciencias; pero para ello es imprescindible actuar en la transformación previa de la epistemología de los profesores.

$\mathrm{Al}$ respecto hay varias tareas concretas: 
- Construir colectivamente con los alumnos diversas concepciones acerca de la ciencia y de los científicos. Pero para ello hay que diagnosticar y criticar primero las concepciones previas de los educandos y las del educador.

- Trabajar por no confundir la transmisión del saber con una formación de científicos; por comprender que a pesar de lo anterior, hay que evitar que el comportamiento docente arruine posibles vocaciones, por ejemplo al mitificar negativamente la ciencia.

- Hacer coherentes las prácticas de aula con concepciones epistemológicamente abiertas, como la actitud interrogadora, la curiosidad, la provisionalidad de la verdad.

- Examinar permanentemente las concepciones previas acerca de la ciencia y establecer ese examen como línea transversal de investigación, para construir otras imágenes de la ciencia, de la actividad científica y de su papel en la sociedad, coherentes con la epistemología actual.

Este artículo debe intervenir entonces como un texto base para la crítica de las lógicas del sentido común y de las concepciones previas de los propios maestros. La apropiación, por ellos, de esta discusión, es una herramienta que debe contribuir a repensar de manera crítica la concepción de proyectos de aula y la planeación curricular.

\section{Cultivar la actitud científica}

De entrada, la misma denominación "actitud científica" niega semánticamente que se trate de un privilegio de algunos seres humanos extraordinarios, como predestinados a alguna misión. Se trata, más bien, de una condición de humanidad. Homo sapiens sapiens se puede definir como ese primate que busca respuestas lógicas a sus preguntas. Es cierto que todos los seres vivos dotados de autonomía, y sobre todo los animales, vivimos experiencias. Éstas nos permiten formar una memoria, entendida ésta como la capacidad de captar y procesar parte de las informaciones provenientes del medio exterior, de nosotros mismos y de otros seres. Nuestra memoria nos permite adaptar nuestros comportamientos, gestos, acciones y decisiones a las contingencias.

Comunicar y percibir son cualidades que los humanos compartimos con el conjunto del mundo animal. Pero la singularidad de nuestra especie, lo que nos distancia de los animales 
es, precisamente, haber adoptado una actitud de interrogación. En efecto, a diferencia de los animales, siempre estamos insatisfechos en nuestra percepción del mundo y de nosotros, y queremos comprenderlo y comprendernos. Intentamos remontar la cadena de causalidades

que han desencadenado el mundo que percibimos, es decir, nos preguntamos por los procesos que se desarrollan y se acumulan en nosotros y en nuestro entorno.

Por otro lado, a diferencia de los animales, que no tienen ni muerte, ni muertos, ni sepulturas, nuestra conciencia de la muerte nos enfrenta desnudos a un destino trágico, pero al mismo tiempo nos ha enseñado que somos esa obra contingente de la vida en la cual ella ha llegado a pensarse a sí misma. Como dice el biólogo Albert Jacquard:

[...] esos mismos encadenamientos ciegos, imprevisibles, brutales, de causa y efectos han culminado de manera provisional, en este pequeño planeta, después de unos quince mil millones años, en un ser capaz de admirar la quietud de los crepúsculos, de embriagarse con la belleza de las rosas, de emocionarse ante una mirada (2005, pp. 11-12).

Esa condición vital, expresada en la conciencia de nuestro ser y de nuestra finitud, no nos puso solamente en situación de contemplación, sino también en situación de interrogación permanente. De ahí que la actitud interrogadora, la actitud científica, no sea una cualidad de niños bien educados sino, más bien, una condición de humanidad. No hay ser humano normal que no pueda ubicarse en este movimiento perpetuo de creación y de innovación que es la ciencia.

\section{Competencias, no competición}

Sin embargo, por mucho que la historia de la ciencia nos haya mostrado, en tantos ejemplos de hombres y mujeres del pasado, la fecundidad de la curiosidad infinita y natural humana, esta última se ve amenazada por la cultura dominante en la actualidad. La cultura occidental, la misma que inventó la ciencia, domina hoy económica y culturalmente el planeta mediante la competencia, entendida como carrera de todos contra todos, que fomenta la competición encarnizada y generalizada entre individuos, entre empresas, entre naciones, entre posturas de pensamiento. No atacamos aquí la competición en sí misma, sino los criterios de éxito que se han elegido y que cada vez más se consideran aplicables en todos los dominios: el lucro, el prestigio social y la eficacia en la consecución de esos 
fines. Aplicados a la ciencia, esos criterios falsean de dos maneras su sentido original y sus objetivos: por un lado, nos hacen creer que la finalidad de la ciencia es volverse eficaz en lo inmediato y en sus aplicaciones, lo que anula su misión primera de comprender el mundo y a nosotros mismos; por otro, esos criterios pervierten a la actividad científica en sus prácticas, las cuales se limitan cada vez más a tareas de corto plazo.

Lo que heredamos de los últimos trescientos cincuenta años son prácticas científicas basadas en el compartir del saber. Es decir, la actividad científica moderna se realiza como una obra colectiva de la humanidad. Lo que se nos quiere imponer con la privatización absoluta de la investigación científica y con la reducción de ésta a la eficacia es una lucha desesperada entre individuos por el poder, por los rubros, por las posiciones frágiles, difíciles de conquistar y fáciles de perder.

En innegable que la eficacia ha sido mil y mil veces necesaria en la práctica científica; pero reducir la ciencia a sus aplicaciones es una manera de empobrecer su futuro. Las preguntas de Galileo, Newton, Darwin, entre otros, no estuvieron guiadas por alguna aplicabilidad inmediata $\mathrm{y}$, sin embargo, ¡cuántos beneficios se han derivado de sus aventuras de conocimiento!

Las renovaciones conceptuales transforman nuestra mirada sobre el mundo y sobre nosotros mismos, orientan nuestra reflexión en direcciones insospechadas y, en ocasiones, tienen consecuencias aplicables, directa o indirectamente. En su práctica y en su interrogación, los investigadores que las hicieron sólo intentaban responder a preguntas inteligentes, mejorar nuestra comprensión del mundo, avanzar en nuestra lucidez y en la comprensión de nosotros mismos, pero quizá no intentaban aumentar o mejorar alguna eficacia inmediata.

La ciencia no tiene por qué ser una actividad rentable, incluso si los sujetos que han podido gozar de formación científica están siempre entre los más competentes del mundo empresarial. La comprensión de la realidad, función humana fundamental y tarea de la ciencia, no se puede reducir a la producción de herramientas para su transformación según criterios de beneficio casi siempre dudosos.

La confusión que la ideología de la eficacia ha introducido en la producción científica es nefasta, pues se ha llegado a confundir el desarrollo de competencias básicas con la 
formación de competidores. En esa contienda se pierde la alegría del comprender y se impone la obsesión por llegar más rápido que otros.

\section{Al respecto, dice Albert Jacquard:}

La introducción del criterio de "velocidad" en una actividad tan sutil como la construcción de la inteligencia hace que la ciencia participe en un movimiento de exclusión (2005, p. 15).

La actitud científica es más bien un terreno por cultivar y no algo que se tenga que adquirir. Desde este punto de vista y oponiéndonos a la obsesión de eficacia y rentabilidad que se ha introducido en la ciencia, pensamos que la formación básica de los jóvenes colombianos debe hacer cada vez más énfasis en la adquisición de principios fundamentales de la ciencia: la curiosidad, la interrogación de la naturaleza, el tratamiento racional de los problemas, la inconformidad frente a las respuestas prefabricadas, el carácter provisional de la verdad... sobre todo para evitar los atajos fáciles que brindan los mitos y las ideologías. Éstos van de las respuestas globales para todo, hasta la eliminación de la posibilidad de elaboración de preguntas.

Por ser dos formas de responder a nuestros interrogantes fundamentales, el mito y la ciencia compiten entre ellos en la asunción de un sistema de pensamiento. Las sociedades democráticas en vías de construcción deben gran parte de sus logros actuales a los principios de librepensamiento, cultivo de la actitud crítica, provisionalidad de la verdad, respeto de la diversidad de puntos de vista, generación de nuevas interrogaciones, todos provenientes del esfuerzo de los científicos, realizados durante varios siglos, por comprender el mundo sin más, sin obedecer a fines previos.

\section{La historia de las ciencias como herramienta}

A menudo, se ha recurrido a la historia de las ciencias como a una herramienta para el mejoramiento de los procesos de enseñanza-aprendizaje. Sin embargo, esas experiencias no siempre han sido exitosas, pues el uso común que se le da a esta disciplina universitaria en los medios escolares ha terminado en ocasiones por volver más pesados los contenidos de la enseñanza. Este problema no se deriva de alguna pesadez intrínseca de la historia de las ciencias, sino del hecho de que el uso más frecuente que se hace de ella es en el sentido 
solamente erudito, respondiendo a preguntas como “¿quién descubrió los microbios?", “¿quién descubrió la fotosíntesis?”, “¿cuándo se descubrió la fecundación?”, “¿quién es el verdadero padre de la teoría de la evolución?". Todo el uso se resuelve entonces en asignarle un nombre, una fecha o algún dato a un descubrimiento, a un concepto o a una teoría. Se trata de un uso poco fecundo de la historia de las ciencias que, al contrario, puede ser más entorpecedor que enriquecedor de los procesos de enseñanza-aprendizaje.

Más que de la historia de las ciencias, el problema parece provenir de dos obstáculos. El primero consiste en hacer uso de cierta historia de las ciencias concebida exclusivamente como relato-memoria de acontecimientos triunfantes, nombres de descubridores enaltecidos como héroes, fechas-hitos, experimentos concluyentes y algunas anécdotas para dar sabor y divertir. Este tipo de historia es el más promovido públicamente entre los no-científicos. Poco se interesa en los procesos que se han dado para llegar a la verdad, en los errores, en las creencias, en los falsos caminos seguidos por los científicos. Presenta un relato triunfalista que hace creer al lector que todo tenía que ser así, y que la verdad estaba como oculta en el núcleo de un rollo que había que desenrollar y desembarazar de las capas no pertinentes. A esta historia la podemos llamar "historia-acontecimiento", en cuanto al relato, pero también la podemos llamar "historia-desciframiento", en cuanto a su postura frente al problema de la verdad. Es inadecuada en la medida en que promueve una imagen mítica de la ciencia y de la actividad científica.

El segundo obstáculo proviene del lugar común establecido respecto a la historia de las ciencias. La imagen que se proyecta de ella condensa muchos de los mitos que se han constituido en torno a la ciencia y al conocimiento. La imagen mediática de la historia de las ciencias no es solamente la de la historia como relato-memoria, sino que recrea imágenes míticas: por ejemplo, el mito del científico del pasado como precursor, un sabio solitario, cual Fausto en su cubil, que desvela los secretos de la naturaleza y pone a los otros en los riesgos del aprendiz de brujo, desafiante de poderes sobrehumanos.

Proyectar imágenes en lugar de hacer comprender pareciera más fácil o más fascinante. En todo caso, la fascinación general por las ciencias no declina y a todos nos gustan los buenos documentales científicos en la televisión, sobre todo los que se ocupan de los orígenes del mundo, de la vida y de nosotros mismos. Basta observar la fascinación 
planetaria por el tema de la aparición de la vida, por el de la extinción de los dinosaurios, por la "explosión cámbrica" o por los innumerables hallazgos recientes de la evolución de la humanidad. Sin embargo, hay un evidente desfase entre las imágenes de ciencia que nos presentan los medios audiovisuales y las de la historia de las ciencias que a veces se usan en medios escolares. El lugar común de la historia-memoria es muy dominante y esto hace que cuando en los manuales y libros de texto de ciencias se recurre a "datos históricos", se lo hace en encuadrados destinados a abrir especies de paréntesis, como hipertextos, con muy poca integración a los problemas que se está estudiando. Esto último marca aún más la separación entre la "verdad establecida" o la "ciencia de resultados" y los datos históricos que aparecen así como superfluos.

Además, el uso del acontecimiento, del descubrimiento, del hecho heroico y de la ciencia de resultados carece de significación en los procesos de enseñanza-aprendizaje, pues equivale a aislar ciertos hechos para atribuirles un valor simbólico, y al hacerlo, se empobrece demasiado la realidad, unas veces privilegiando algún hallazgo que se ha aceptado como verdad vigente en ciencia, otras veces polarizando la atención hacia un problema falso, muchas veces cargado de nacionalismo.

Esa construcción de hitos y símbolos corresponde más a las formas de funcionamiento del mito que a las operaciones racionales de la ciencia. Un ejemplo sorprendente es el de la construcción social y cultural del mito "Louis Pasteur, salvador de la humanidad", relato que ha llegado a opacar todas las demás trayectorias de este científico como hombre, padre de familia, actor político y cultural, profesor, jefe de laboratorio y funcionario de la educación nacional.

El tipo de mitos que construye esta forma de usar la historia de las ciencias (historiaacontecimiento e historia-desciframiento) impide en parte la comprensión de lo que es la ciencia, de los procesos que ella ha vivido para la construcción de sus edificios teóricos y de una manera de reflexionar sobre el mundo, los seres y las cosas. Estos mitos fundacionales forman una especie de pantalla que impide a los estudiantes y educadores, el cultivo de la actitud científica, el acercamiento a las formas de racionalidad de la ciencia (remplazándolas por operaciones propias del mito, quizás más cómodas), así como el acercamiento a la reflexión filosófica. 
La propuesta de utilizar otro tipo de historia de las ciencias, a la que podemos llamar historia epistemológica de las ciencias, que implica las formas de racionalidad de las ciencias, la ciencia como labor experimental, como tentativa de análisis de verdades y teorías provisionales, que en su búsqueda genera nuevas preguntas en lugar de dar respuesta a todo, obedece al interés de introducir el conocimiento de los procesos de construcción del saber científico en el aula de clase. Se enfoca más en la genealogía de conceptos y teorías que en el enaltecimiento de unos hitos en menosprecio de otros.

También se interesa esta propuesta en el uso del error en ciencias como herramienta de comprensión filosófica. Lo que más nos interesa es mostrar, a partir de la sociología y la historia de las ciencias, cómo actúan los científicos, cómo trabajan, cómo interrogan la naturaleza, cómo se acercan sus preguntas a las de la filosofía y también de qué manera esta última disciplina nos muestra los problemas del proceso de conocimiento basado en las racionalidades de las ciencias.

\section{La actitud científica como crítica del sentido común}

En cuanto a estas tareas, queremos dejar claro que nuestra perspectiva se sitúa en el deber de privilegiar la enseñanza de las ciencias en todos los niveles de la escolaridad, en pro de la formación de ciudadanos dueños de sus decisiones y opiniones. Ésta es una posición filosófica y política en contra de los sectarismos, los fanatismos y las cómodas vías de explicación de los fenómenos naturales, sociales y culturales según la formación de mitos y estereotipos.

De ahí que invitemos a los maestros y maestras a interesarse en los procesos de construcción de lugares comunes y de opinión; es decir que, como científicos, nos interesemos en interrogar los procesos de formación de mitos y representaciones culturales, en nuestro entorno más inmediato y en el aula de clase. Asimismo, nos interesan, dentro de los procesos de enseñanza-aprendizaje, las relaciones complejas que se tejen entre las representaciones individuales, las representaciones colectivas y las adquisiciones de la ciencia contemporánea. Para la comprensión de estos procesos, la historia genealógica de los conceptos y las teorías, la que se interesa en los procesos de construcción de la verdad, 
es una especie de laboratorio que hay que abrir para la discusión con los maestros de primaria y secundaria.

Nuestras recientes experiencias con maestros de regiones antioqueñas y de la costa atlántica, nos han mostrado la fecundidad de esta propuesta de introducción del estudio de la genealogía de conceptos en el aula de clase. También hay que entender que la propuesta es novedosa en el contexto colombiano y que sólo tiene la pretensión de introducir problemas allí donde todo aparece como uniforme, pesado y rutinario. La introducción de problemas o la implicación de los educadores y educandos en problemas es una de las tareas de la filosofía contemporánea: pensamos que esta disciplina se ha renovado en sus tareas en el mundo de la educación, mediante la tarea de cultivar la actitud crítica, la actitud científica frente al mundo y las formas de interrogación propias de la racionalidad moderna.

\section{Referências Bibliográficas}

GIORDAN, André; RAICHVARG, Daniel . Del descubrimiento a la construcción de conceptos. IN: GIORDAN, André (Ed.), Conceptos de biología I. Barcelona: Labor, 1988. $2 \mathrm{v}$.

JACOB, François. El juego de lo posible. Barcelona: Grijalbo, 1982.

JACQUARD, Albert. La ciencia para no científicos. Buenos Aires: Siglo XXI, 2005. 